\title{
Farming with Electricity
}

\author{
A Hundred-Thousand Acre Tract That Is Fully Equipped with Modern Machinery \\ By Ralph Howard
}

$\mathrm{H}^{\mathrm{OW}}$ the barrenness of the desert has responded story of the West, the Goverument project embracing 121,310 acres in Cassia and Minidoka Counties, Idaho, being a notable illustration. The astonishingly swift transformation of this once vast area of desolation into a fertile farming region-all within 13 yearsis an inspiring achievement of itself, but of more singular distinction is the conspicuous rôle that electricity is playing in the farm homes of this big agricultural community. With 1,100 farmers applying electric current in producing and harvesting their crops, doing the chores of the housewife, and illuminating and heating the homes, schoolhouses and churches, no other rural section in the United States has accorded such all-embracing favor to this form of power as has this hydroelectric project in south central Idaho.

Electricity as a servant of city dwellers is of increasing popularity, but its common adaptation to rural life is a dream of future accomplishment. Its use in agricultural areas is a novelty, restricted to isolated examples in progressive communities. Herein the Minidoka enterprise, administered by the Reclamation Service of the United States Department of Interior, takes a radical departure. Electric current be comes an agent of almost universal recognition in an expansive rural area, where the most populous town, Burley, claims only 4,000 inhabitants. Rupert, a village of ranking importance, has barely 2,500 souls; the two mentioned burgs being products of the reclaiming powers which extended its magic wand over 121,310 powers which extended its magic wand over 121,310 yielding a wealth of alfalfa, potatoes, sugar beets, small grains, as well as nurturing a beef and dairy cattle industry. No manufacturing industries of consequence are fostered; two beet-sugar factories, a potato dehymills, constituting the magnitude of manufacturing. All of which brings into relief the aspects of a slogan

\section{Correspondence}

The editors are not responsible for statements made in the correspondence column. Anonymous communications cannot be considered, but the names of correspondents will be withheld when so desired.

\section{The Einstein Contest}

To the Editor of the Scientific American:

It is a real pleasure to read the prize essay on the Einstein theory and note the absence of weird mathematical symbols. One who has completed the ordinary college mathematical courses including calculus, feel that he has a real grievance when he encounters strange mathematical symbols, with no hint as to what they mean or how their meaning can be found at the library. He may also have a sneaking suspicion that the thirteen super-minds might be slipping something over. Having hastily suppressed that thought, perhaps he recalls instances where he himself has used mathe matics to solve a problem and found that there was more than one answer. Perhaps one of the answer involved $V-1$ known as an "imaginary" answer, or would be even stranger than those of the Einstein theory. All of which confirms the proverb that mathematics is a good servant but a bad master.

The statement that a vard-stick changes its length when turned around $90^{\circ}$, and that a watch runs at a different rate when on a fast train, will not be accepted by the skeptics on the mere statement that it is so, nor on proof so entirely mathematical as to be beyond control. Of course the essayist could not be expected to prove anything. He was only expected to explain, and this he has done so well that he, Mr. Hig gins and
credit.

The weak point is the failure to state definitely the fundamental assumption on which the entire theory is founded, viz.: that the absolute velocity of light (in a vacuum ) is constant. In other words that all space is filled with a fixed ether that does not partake of the motion of the earth. This ether was invented long ago to explain the transmission of light. A very attenuated kind of super-gas will not answer the require- of the city, "Do it electrically"-applied on the farm. The engineering equipment includes a diversion, power and storage dam on Snake River, 7 miles south of Minidoka, two canal systems, one on each side of the gravity system embraces 72,348 acres. The power
plant is a creature of necessity in pumping water to approximately 50,000 acres during the irrigation seatry dwellers is a by-product. Of the 3,000 consumers of electricity, 1,100 are honest-to-goodness farmers. Substations have been built and distributing stations have constructed 290 miles of 2,200-volt circuits, extending 250 miles through rural communities. Although avoiding extensive retailing of electric power, the Reclamation Service takes the initiative in the organization of companies composed of farmers, which are incorporated and operate as mutual enterprises under the statutes of Idaho. These operating units build their own 2,200-volt lines, install transformers, and dispense current to individual consumers. The Federal Government acts as a wholesale distributor of power which is obtainable at substations conveniently located on the 30,000 -volt transmission system.

The energy as supplied wholesale by the Department of Interior to farmer companies is based on a charge of $\$ 2$ a month per kilowatt of maximum demand for the equivalent of the first 50 hours' use of the maximum demand for the month; 3 cents a kilowatt-hour for the next 50 hours' use of the maximum consumption; 2 cents per kilowatt-hour for the succeeding 50 hours consumption of the ultimate needs; 1 cent a kilowatthour for the next $\mathbf{1 5 0}$ hours' use of the maximum requirements; and $1 / 2$ cent a kilowatt-hour for all energy used in excess of 300 hours' use of the supreme needs. The rate also recognizes a block discount based on the contractor's guaranteed maximum demand, increasing from 2 per cent for 2-kilowatt contracts up to 30 per river at the diversion dam, and three main pumping stations. There are 634 miles of canals, and the son; thereby, the electric current distributed to coun-

cent for a contract of 100 kilowatts or more. Likewise a discount of 10 per cent is granted wherever energy is delivered and measured at 2,200 volts. A rural distribution line, including accessories, can be built at an expenditure ranging from $\$ 500$ to $\$ 1,000$ a mile; ordinarily four farms being linked for each mile connected to the circuits. The farming unit is 80 acres. Twenty farm companies have been organized, supplying approximately three-fourths of the rural consumers. Other users receive their electric current from lines vitalized by the systems of the various towns, barring 40 farmers who obtain a supply direct from the Government on individual contracts.

Interesting observations have been assembled as the results of study of the distribution of electricity on this Government project, which is the premier rural consumer in the United States. The use of a diversity of electrical appliances improves the load factor, and formers floating on line likewise enhances the load factor. The load tests indicate that the companies' peak burden is always at the time of the lighting peak. The individual farmer consumer has a day peak, which averages three times his average night peak. The diversity of the day burdens, however, is such that the excessive individual needs do not affect the companies' maximum demand. The companies' evening peak is three to five times greater than the day load. The power factor of a rural company rarely exceeds 50 per cent except during the evening lighting peak. Distribution losses in kilowatt hours range from 30 to $\mathbf{5 0}$ per cent, primarily attributable to the energizing current of the transformers. One-half of the rural distribution systems employ iron wires for conductors. The largest company on the project serves 165 farmers on 38.5 miles of line, comprising 13 miles of 3 -phase No. 6 copper wire, 3 miles of 3 -phase No. 8 iron wire, 3 miles of single-phase copper, and the remainder single(Continued on page 399 )

ments. It must be a solid body, vastly more rigid than the strongest steel, and yet allow the earth to pass right through it without offering the slightest resistance and without being displaced the slightest amount by the earth. In accepting such an ether, one is simply forced to make some mental reservations. Perhaps it should be taken in the sense of the familiar comparison between electricity and a circulating system of water pipes. It can't be taken too literally.

While such a fixed ether explains nearly all the facts about light, it does not explain quite all. It is directly contradicted by the measurement of the aberration of contradicted by the measurement of the aberration of
light, with a telescope filled with water. The ether light, with a telescope filled with water. The ether
theory is not so well established but that it is still subject to minor modifications. The ether, for example, may not be fixed; some of it may be carried around with the earth, and there have been other suggested modifications of the ether that would entirely upset the Einstein theory.

With a fixed ether, of course the earth would sweep through it at some 18 miles a second, in its orbit around the sun. At midnight the ether would seem to us to be coming from the east. Its direction would change, as the earth rotates on its axis, so that by morning it would seem to be coming down on our heads.

This is the way the ether was supposed to be sweeping through the laboratory while Michelson and Morley measured the velocity of light. Yet it was found that the apparent velocity of light was the same at all hours. and that is right where the trouble started that is and that is right where the

To the normal mind this experiment simply showed that the ether was not rushing through the laboratory at 18 miles a second. Einstein's deductions are all the proof that is necessary that the laboratory was not moving through the ether at all. But the German mind when confronted with the discrepancy between the theoretical result and the experimental result, instead of seeing that one or the other result must be wrong, saw that both results were right and all the rest of the world wrong. So the discordant results were equated to each other, the equation was solved, the interpretation of the solution was proclaimed, and the world was plunged into mental anarchy

But let us make another experiment. This one won't cost anything because the skeptics will agree with the super-minds as to the outcome and will disagree only on the explanation. Let us take two clocks: one with a balance wheel escapement, the other with a pendulum escapement. The axis of the balance wheel will be placed parallel to the axis of the earth. We will neglect the velocity of about a quarter of a mile a second due to the rotation of the earth on its axis and assume that the motion of the axis of the balance wheel through space is uniform. The time rate of this clock will therefore be uniform. The pendulum of the other rate at noon and midnight when its motion through space is transverse. But in the morning and evening its motion through space will be endwise, and Einstein tells us that its length will shorten. Therefore it ought to beat faster. If the earth's radius also shortens, gravity ought to get stronger and cause the pendulum to beat still faster. Every one will agree that the two clocks will actually keep together. To the skeptics there is nothing about this to explain. It is up to the super-minds to show posed change in length; presumably by amending the law of gravitation. It would be very interesting to know how this can be done without annuling their proof of the motion of the planet Mercury. But we will never know; because if they should answer this question it would be with another flock of weird symbols of unknown meaning. GILBERT S. WALKER. New York.

\section{The Knife and Fork in One}

To the Editor of the Scientiric American:

In a recent issue I saw a description of a "new" combined knife and fork for the use of maimed soldiers. I think, but am not sure, that the implement in question was sold by Gamage of London. Eng., long before the Great War.

It is a very old tool; by the courtesy of MIssrs. Read of Dublin, I was allowe to make a tracing of their model, the age of which is uncertain, but well over 120 years. This firm sells occasionally to special customers razors, knives (all descriptions) and scissors guaranteed over 100 years old. The steel is known to the color of silver, and retains the edge for years without regrinding, or in the case of razors, resetting. The business was started 273 vears ago and has continued without a break.

Loughrea, Ireland.
(Rer.) R. W. Talbot. some effect that would exactly compensate for the supthem as "silver steel," is of magnificent quality, polishes 
LEGAL NOTICES

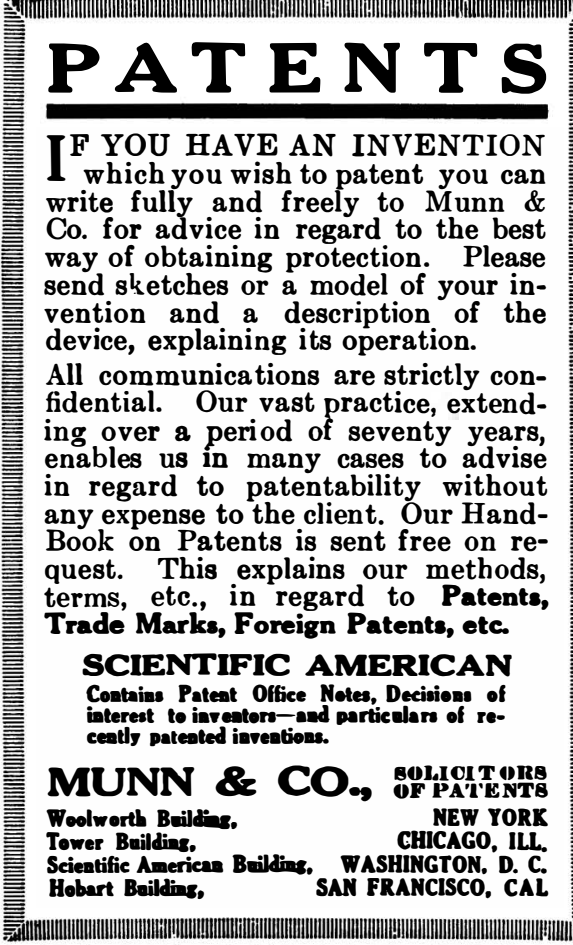

Annual Subscription Rates

Scientific American Publication

Scientific American (established 1845) one

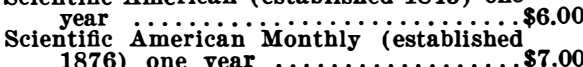
Pastage prepaid in United States and posses

Foreign Postage
Scientific American $\$ 1.50$ per year additional.
Scientific American Monthly $72 \mathrm{c}$ per year ad-

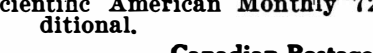

Cecientific American 75 c portage
Scear additional.
Scientific American Monthly 36 ce per year add The combilined subscription rates and rates
foreign countries including Canada, will be Remit by postal or upon apps money order, bank

Classified Advertisements

Advertising in this column is $\$ 1.00$ a line acepted Count seven words to the line. All
orders must be accompanied by a remittance. BUSINESS OPPORTUNITY

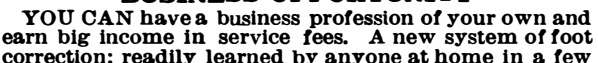
weeks. Easy terms or training; openings everywhere
with all the trade you can attend to. No capital re quired or goods to buy, no agency or soliciting. Addre
Stephenson Laboratories 23 Back Bay, Boston, Mass. BUSINESS OPPORTUNITY

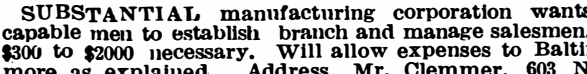
more as expolained i. Adress, Mr. Clemmer, $603 \mathrm{~N}$
Eutaw St., Baltimore. Md.

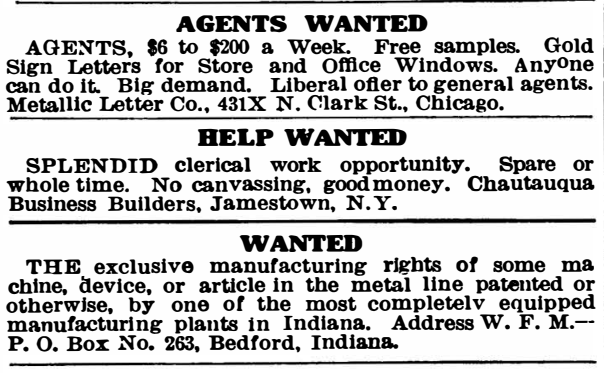

SAVE FUED AND OIL carbon. Will greatly improve engines, pumps, com
pressors, ets. Send for free Evidence Booklet. Ever-
Tyto Piston

\section{Page Catalogue of SCIENTIFIC AND TECHNICAL BOOKS}

Listing 2500 titles on 500 subjects SELECTED from more than 7,000 Books still
in print. This catalogue is the latest and
best list of technical and scientific literature
which can be secured. Conditions in the pubwhich can be secured. Conditions in the pub-
lishing business are most severe and it is with
difificulty that many books can be obtained. For this reason this timely catalogue of books which
can be had will be par ticularly welcome. Write to-day for your copy. SCIENTIFIC AMERICAN PUBLISHING CO.
233 Broedway, Woolworth BIdg.
Fuel Conservation Opinions-II (Continued from page 397)

ones. Already power plants are being ocated at the mines, so as to eliminate distribute electric power to the erstwhile coal consumers over quite an area. Again small power plants in thickly populate sections of the country are gradually becoming substations of larger plants. Indeed, there are ample signs that the super-power zone idea is gaining ground, automatically and without attractin much attention, to be sure.

The Fuel and Power of Tomorrow

Speaking of new fuels and sources of power, it is interesting to learn that Callfornian power plants have recently been offered a new fuel-crude oil residueoil by breaking the crude oil down into it constituents to a greater degree than has heretofore been the practice. The problem of suitable storing and firing methods for this new fuel is at the present time being studied. The quantity of its supply is limited, since it will be a by product from the distillation of crude oil ing with interest the development of powdered fuel and colloidal fuel, which is now going on; but it is difficult to obtain a definite opinion as to the probable future of these fuels.

Lignite, even of the low grade North Dakota variety, will undoubtedly be more generally used in the near future, we are
told by other authorities. Heretofore stoking equipment had not been developed that would burn the lignite satisfactorily but the advent of recent automatic stokers has provided a means to utilize this cheap, low grade fuel, and an increased use
lignite can be confidently expected.

lignite can be confidently expected.
Our attention is directed to the great possibilities of obtaining higher efficienc from the fuels now used and the saving of the by-products, as well as the expanding area of oil-producing sands and shale; also, there are possibilities for methyl alcohol and other fuel products Indeed, if we grasp the idea of certain authorities correctly, it would seem that we are only at the doorway of Nature's storehouse, and that we might well learn first to make the most out of our present fuels before we seek new varieties. There is little doubt but that we shall be using poal and gasified coal in everfuture, after first extracting the valuable by-products, thus substantially reducing the cost of the fuel by obtaining certain by-products that are not permitted to go to waste. But before much progress can be made along these lines, the problem as a whole should receive considerable publicity and no end of study.

Edison suggests that the volcano and hot spring areas in the United States might give considerable power by means of deep bore holes and turbines. Th scheme, it will be recalled, is in successful commercial use in Italy.

But it is a fact that human nature never seeks a definite solution of a problem until the problem becomes acute There may be exceptions-Germany's development of her brown coals is an example, a very rare and worthy example, goes without saying; but as a genera thing the users of fuel are content in the assurance that of bituminous and anthracite coals, of petroleum and the lighter oils, of alcohol and of natural gas, and of all the other fuels which we are usin today, there is an ample supply for many years to rome. Hence the prevalent in plied attitude. Why worry?

Farming with Electricity (Continued from page $38 \%$ ) phase iron. The connected load is 250 kilowatts, which is carried by 200 kilowatts of distribution transformers. The maximum use of energy occurred in April, livered from the substation to the company's feeders with a recorded maximum demand for 35.2 kilowatts

The housewife shares generously of the benefits accruing from the application of electrical labor-saving devices on these Idaho farms. Many homes have been conserving the purposes of illumination and heating, as well as the operation of the washing machine, sewing machine, and cooking appliances. Even the offspring of Mother Hen is warmed by current generated from the power plant, a carbonfilament lamp being installed in the supply water to the homes, and the farmer hooks a motor to a jack shaft which drives the pump, cream separator grindstone, feed grinder, and other use ful machinery. The electric iron enjoys almost universal popularity, there being 1,862 flatirons in use. The washing machine is operated by electricity in 875 of the homes of the rural consumers. Vac uum cleaners, curling irons, ranges, moving picture machines, coffee urns, percolators, fans, water heaters, adding machines, vibrators, bake ovens, sterilizers, air warmers, and heater pads are among the electrical appliances in use. Seventy per cent of the residents on this Government project being owners of sheep, electrity for pumping water to the stock 5,141 electrical appliances are in use, their popularity being represented by a 54 per ent increase within twelve months.

When Oysters Are in Season (Continued from page 388)

from New York and New England to foreign countries involves the use of barrels containing three bushels and one-half peck, the container having a head. Hotels and restaurants serve oysters on the half shell, the "Blue Points" from beds of a cape on the south side of Long Island enjoying a distinction when thus placed on the menu. Likewise oysters are shipped Pacific shell from eastern waters to the

Shucking is described as the prosess divorcing the meaty contents from the shells, tables or stalls in oyster house being assigned for the separation proceed ings. The water products are conveyed to the tables by wheelbarrows, in small ter houses, th. In more pretentious oysa storage room and let down through chutes to the individual stalls of shuck ers. The operator stands on a bench before the table, upon which the shell fish tumble from the descending movemen through slanting chutes. Blocks are accessible for placing the oyster for opensites for shucking. power are requion the left hand to avoid contact with the knifed edges of the shell, the hand of the shucker moving with incredible speed. A knife is used in prying the shell apart. From ten to twelve gallons constitute a reasonable day's work. The meaty contents are deposited in a galvanized-iron container, while the shells gain admittance to a trough in the shucking table whence they are transported for concentration by a mechanical carrier. The meat of the fish may be then robbed of its excess fluid by perforation. In small oyster houses the shells are deposited on the floor alongside the shucker and later removed in wheelbarrows. A movable wooden stall, 18 or 20 inches wide, quarters the operator and protects him from the accumulating mountain of shells. Dur ing the season of 1919-1920, shuckers were paid from thirty-five to forty cents a gallo

Once deprived of their shell-enclosed home, the meat of the oyster is placed on washing tables. Simple in construction these units are made of galvanized iron, measuring 5 feet long and $21 / 2$ feet wide, and supported on a wooden framework Water drainage is effected through a per-

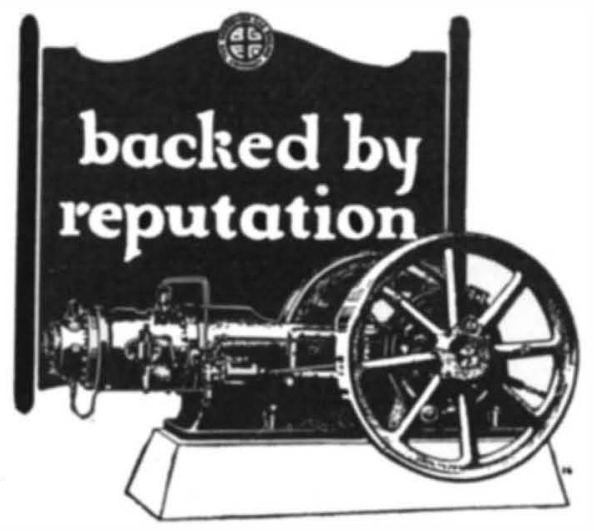

CHE good name of Bessemer has been won through years of uninterrupted quality pro-
duction. On every Bessemer product, the
Begsemer trademark has come to mean more than a mere symbol of identification. On oil engines, it is your guarantee of dependable grade of fuel oil. 15 to $180 \mathrm{H}$. P. Write for catalog. THE BESSEMER GAS ENGINE CO. 14 York Street Grove City, $\mathrm{Pa}$.
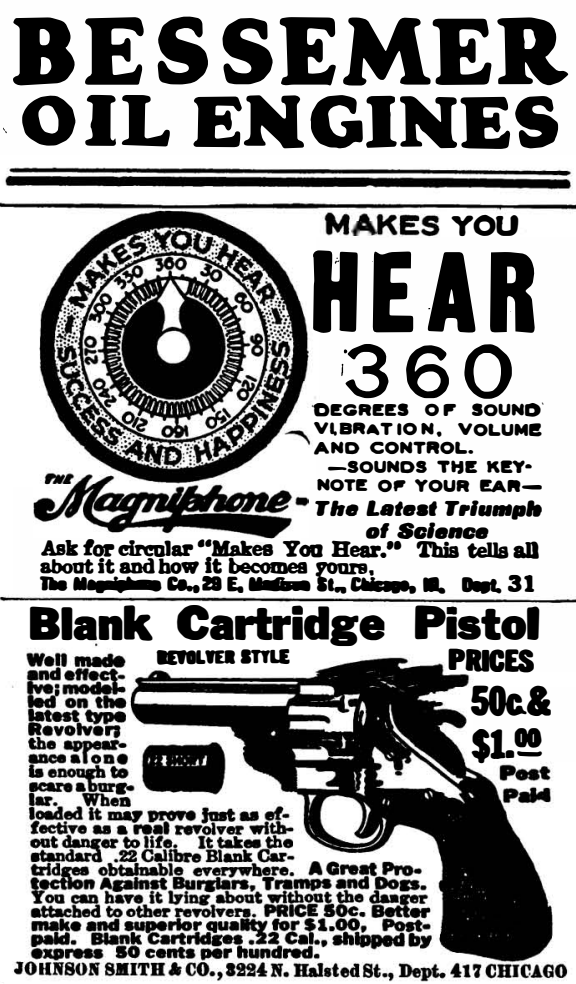

BEATS I5o GASOLINE Increases Power and Mlleage 40\% Amaxing anto invention. Wonderful
new carburetor. Guaranteed to re-
duncegasoline bills from one--haip to
one-third and increase power of ang G O O Sent on 30 DNYS' TRILL

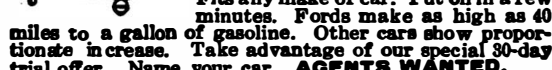
offer. Name your car. AGENTS WANTED
AlR FRICTION CARBURETOR CO. 1361 medizon Etroot OART Dayton, Onlo

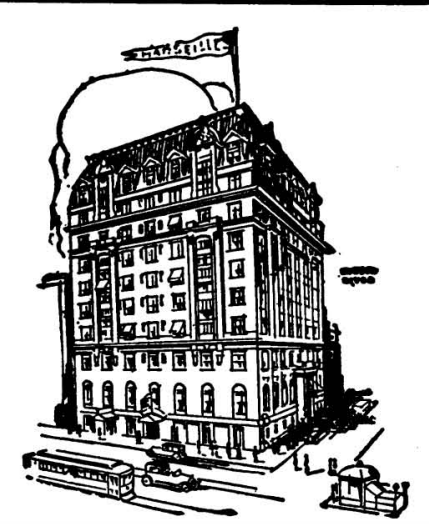

喢otel Alargeilles

BROADWAY at 103rd ST., NEW Y OR K CITY

“A Hotel of Di Express Station

Between Riverside Drive and Refinement"
Coolest location in New York Park

Ten minutes by subway to 42 2nd Street and 20
minutes to wall Street

minutes to Wall Street
Attractive rooms single or en suite

DINING ROOM AND GRILL
A la Carte and Table d'Hote Service

M. P. MURTHA, Manager 